\title{
Metallo-macrocycle Camouflages: Multi-Colored Electrochromism in a \\ Fe(II) based Metallo-Supramolecular Macrocycle Utilizing the Redox of Metal Centers and Carbazole Containing Ligand
}

Susmita Roy and Chanchal Chakraborty*

Department of Chemistry, Birla Institute of Technology and Science (BITS) Pilani, Hyderabad Campus, Jawahar Nagar, Shameerpet Mandal, Hyderabad-500078, India Email: Chanchal@hyderabad.bits-pilani.ac.in 


\section{Content}

1. ${ }^{1} \mathrm{H}-\mathrm{NMR}$ of 3,6-dibromo-9-hexyl-9H-carbazole (N-hex-Cz):-----------S3

2. ${ }^{13} \mathrm{C}-\mathrm{NMR}$ of 3,6-dibromo-9-hexyl-9H-carbazole (N-hex-Cz):-------------S4

3. ESI-MS of 3,6-dibromo-9-hexyl-9H-carbazole (N-hex-Cz):-------------S4

4. ${ }^{1} \mathrm{H}-\mathrm{NMR}$ of 3,6-bis(4-([2,2':6',2''-terpyridin]-4'-yl) phenyl)-9-hexyl-9H-carbazole (N-hex-Cz-tpy):

5. ESI-MS of 3,6-bis(4-([2,2':6', $2^{\prime \prime}$-terpyridin]-4'-yl) phenyl)-9-hexyl-9H-carbazole (N-hex-Cz-tpy):--------------------------------------------------------------------S6

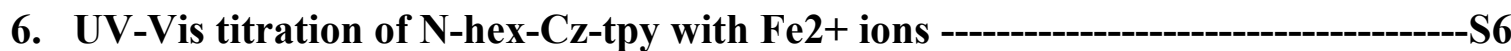

7. ${ }^{1} \mathrm{H}-\mathrm{NMR}$ of $\mathrm{Fe}-\mathrm{Cz}-\mathrm{MC}$ :---

8. MALDI-TOF mass spectra of $\mathrm{Fe}-\mathrm{Cz}-\mathrm{MC}$ :-----------------------------------S7

9. ESI Mass spectra of $\mathrm{Fe}-\mathrm{Cz}-\mathrm{MC}$ :---

10. Emission spectra of $\mathrm{Fe}-\mathrm{Cz}-\mathrm{MC}$ in solid state -----S8

11. Cycle switching stability of EC measurement of Fe-Cz-MC film using three

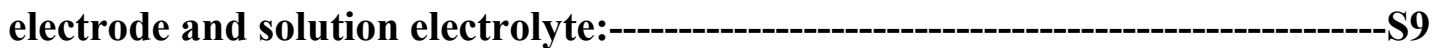

12. Thickness measurement of solid state EC film by FESEM --- 
1. ${ }^{1} \mathrm{H}-\mathrm{NMR}$ of 3,6-dibromo-9-hexyl-9H-carbazole (N-hex-Cz):

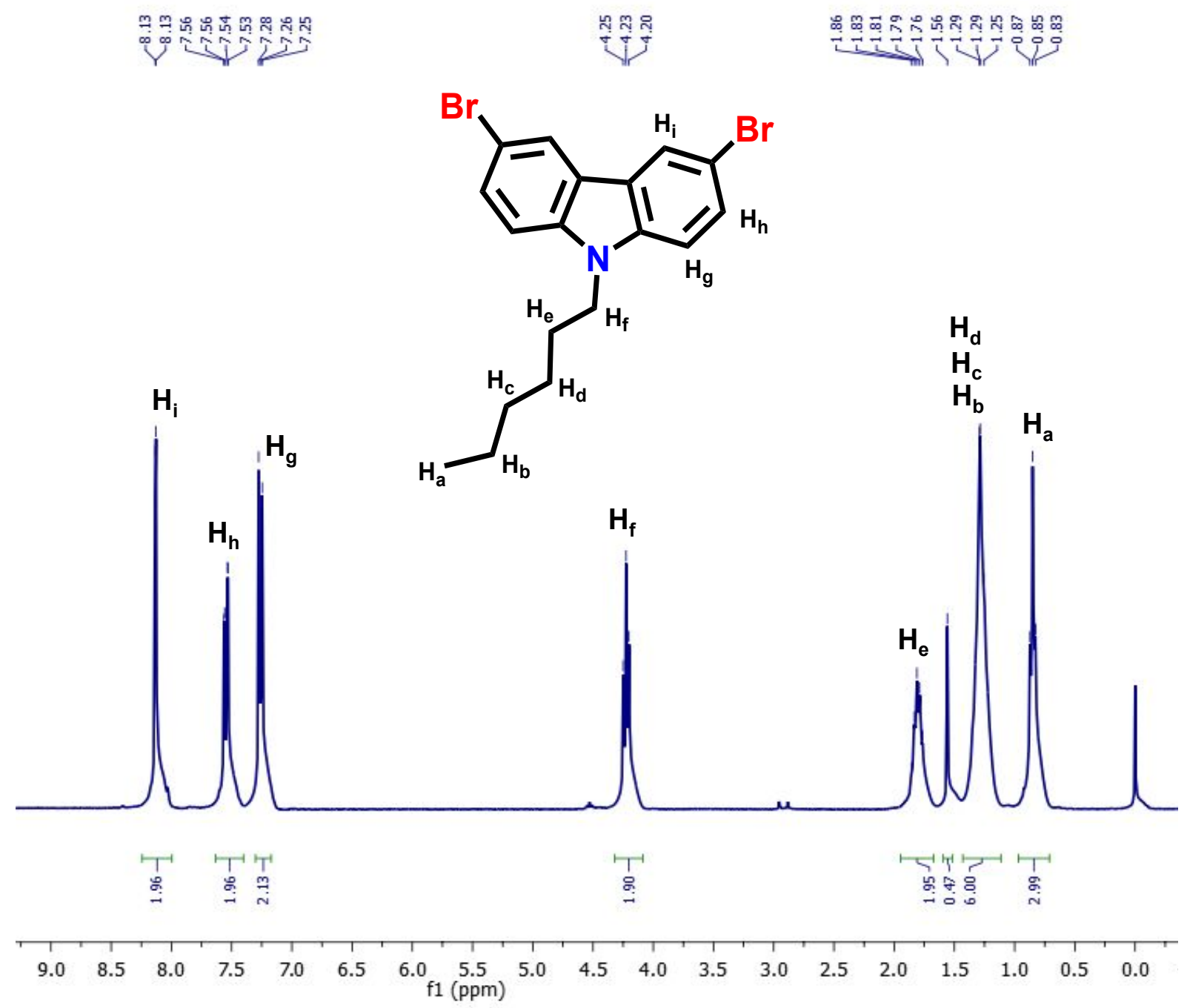

Figure S1. ${ }^{1} \mathrm{H}-\mathrm{NMR}$ of 3,6-dibromo-9-hexyl-9H-carbazole in $\mathrm{CDCl}_{3}$ at $400 \mathrm{MHz}$. 
2. ${ }^{13} \mathrm{C}-\mathrm{NMR}$ of 3,6-dibromo-9-hexyl-9H-carbazole (N-hex-Cz):

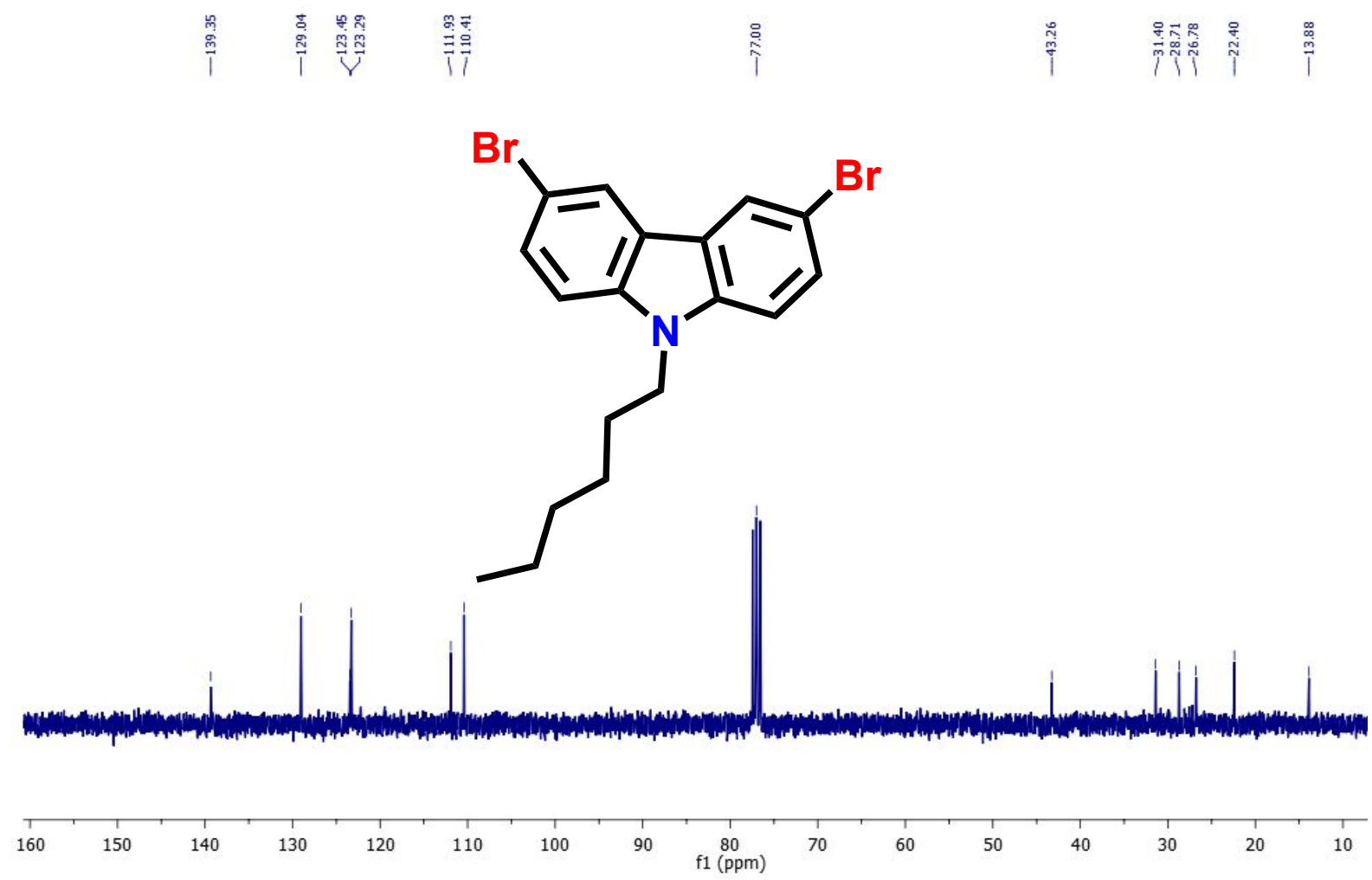

Figure. S2 ${ }^{13} \mathrm{C}$-NMR of 3,6-dibromo-9-hexyl-9H-carbazole in $\mathrm{CDCl}_{3}$ at $100 \mathrm{MHz}$.

3. ESI-MS of 3,6-dibromo-9-hexyl-9H-carbazole (N-hex-Cz):

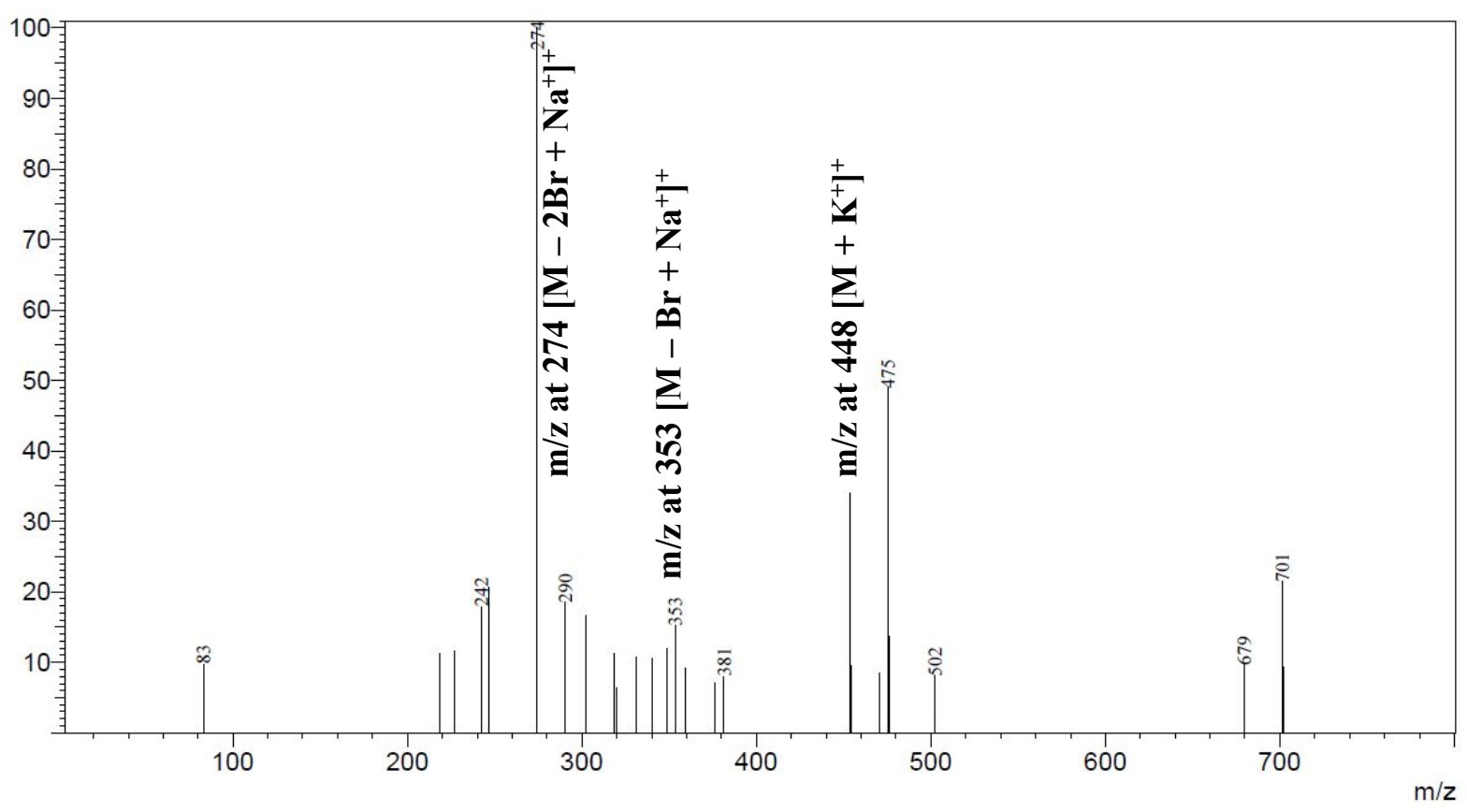

Figure S3 ESI-MS of 3,6-dibromo-9-hexyl-9H-carbazole. 
4. ${ }^{1} \mathrm{H}-\mathrm{NMR}$ of 3,6-bis(4-([2,2':6',2'"-terpyridin]-4'-yl) phenyl)-9-hexyl-9H-carbazole (N-hex-Cz-tpy):

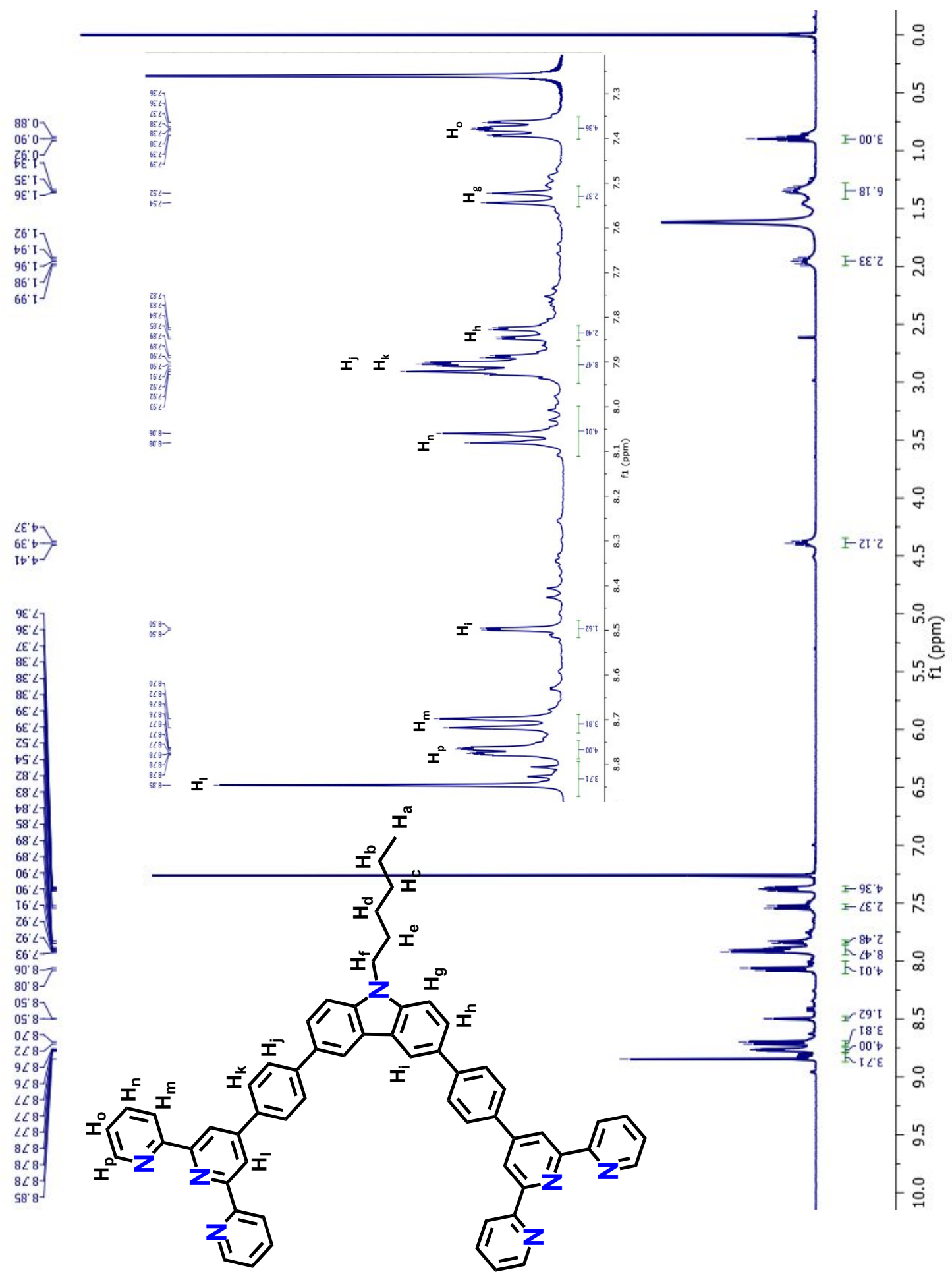

Figure S4 ${ }^{1} \mathrm{H}-\mathrm{NMR}$ of 3,6-bis(4-([2,2':6',2"-terpyridin]-4'-yl) phenyl)-9-hexyl-9H-carbazole (N-hex-Cz-tpy) in $\mathrm{CDCl}_{3}$ at $400 \mathrm{MHz}$. 


\section{ESI-MS of 3,6-bis(4-([2,2':6',2'-terpyridin]-4'-yl) phenyl)-9-hexyl-9H-carbazole}

(N-hex-Cz-tpy)

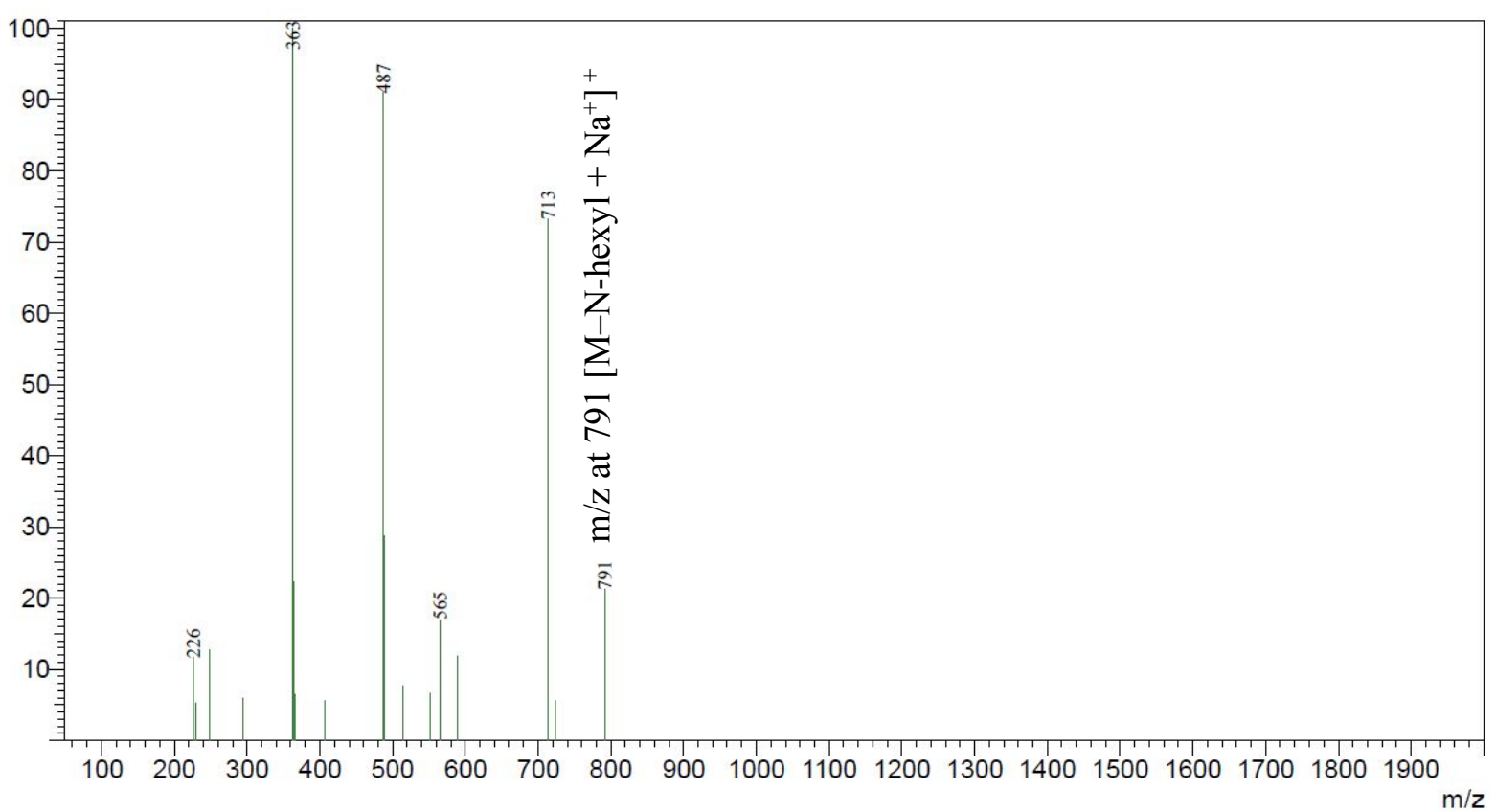

Figure S5 ESI-MS of 3,6-bis(4-([2,2':6',2"-terpyridin]-4'-yl) phenyl)-9-hexyl-9H-carbazole (N-hex-Cz-tpy)

\section{UV-Vis titration of N-hex-Cz-tpy with $\mathrm{Fe}^{2+}$ ions}
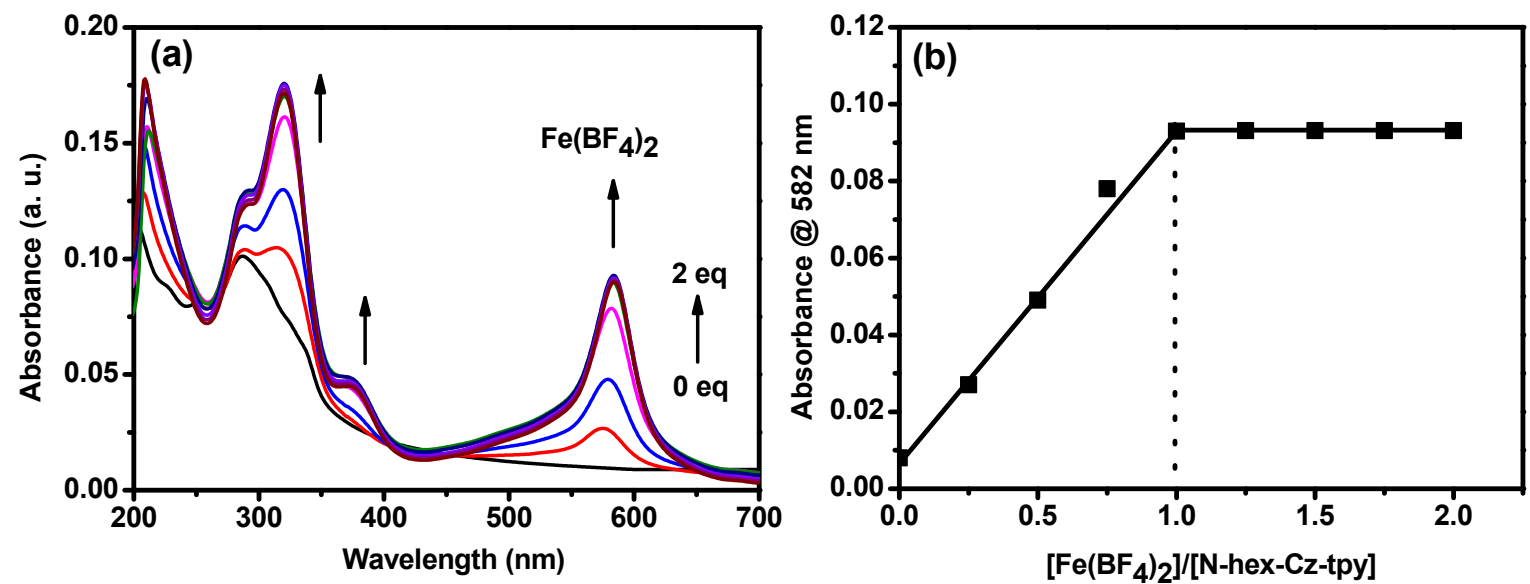

Figure S6. (a) UV-vis spectral change of a methanol solution of N-hex-Cz-tpy during titration with $\mathrm{Fe}\left(\mathrm{BF}_{4}\right)_{2}$ at room temperature. (b) The absorption change at $582 \mathrm{~nm}$ as a function of the $\left[\mathrm{Fe}\left(\mathrm{BF}_{4}\right)_{2}\right] /[\mathrm{N}$-hex-Cz-tpy] ratio. 


\section{7. ${ }^{1} \mathrm{H}-\mathrm{NMR}$ of $\mathrm{Fe}-\mathrm{Cz}-\mathrm{MC}$ :}

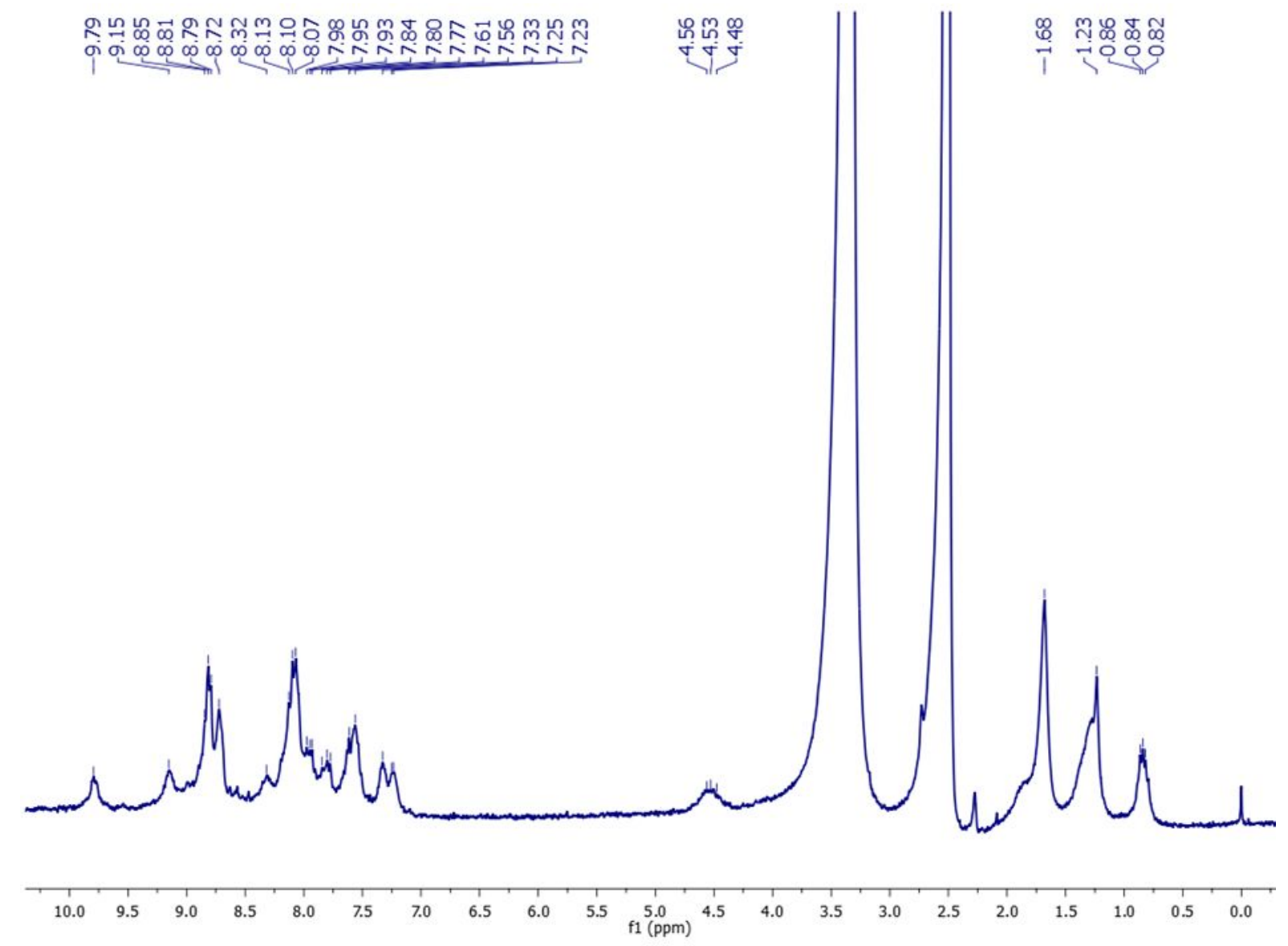

Figure S7. ${ }^{1} \mathrm{H}-\mathrm{NMR}$ of Fe-Cz-MC macrocycle in DMSO-d ${ }_{6}$ at $400 \mathrm{MHz}$.

8. MALDI-TOF mass spectra of $\mathrm{Fe}-\mathrm{Cz}-\mathrm{MC}$ :

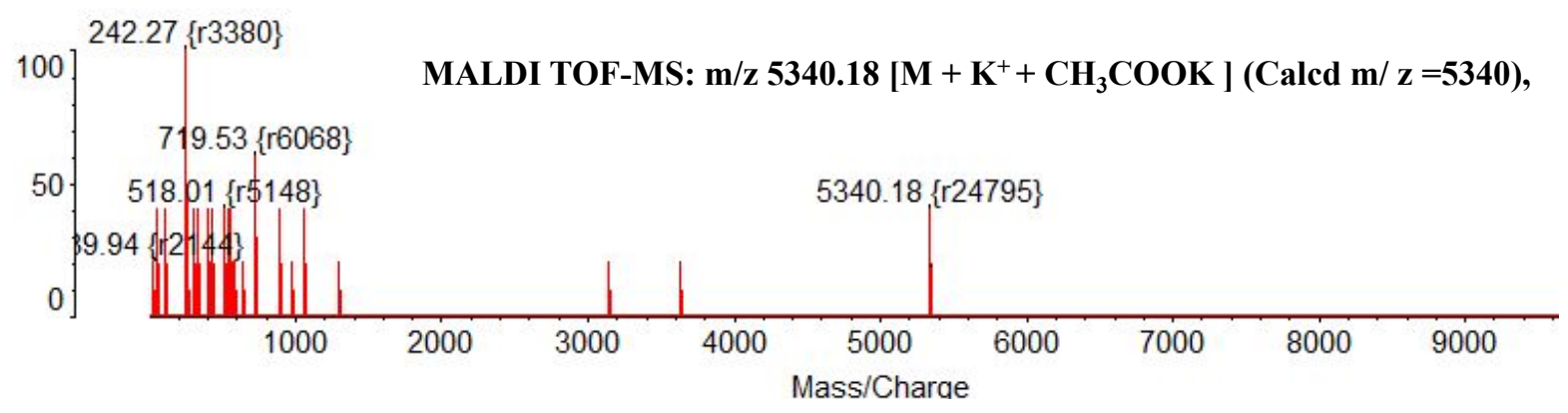

Figure S8. MALDI-TOF mass spectra of Fe-Cz-MC 
9. ESI Mass spectra of Fe-Cz-MC:

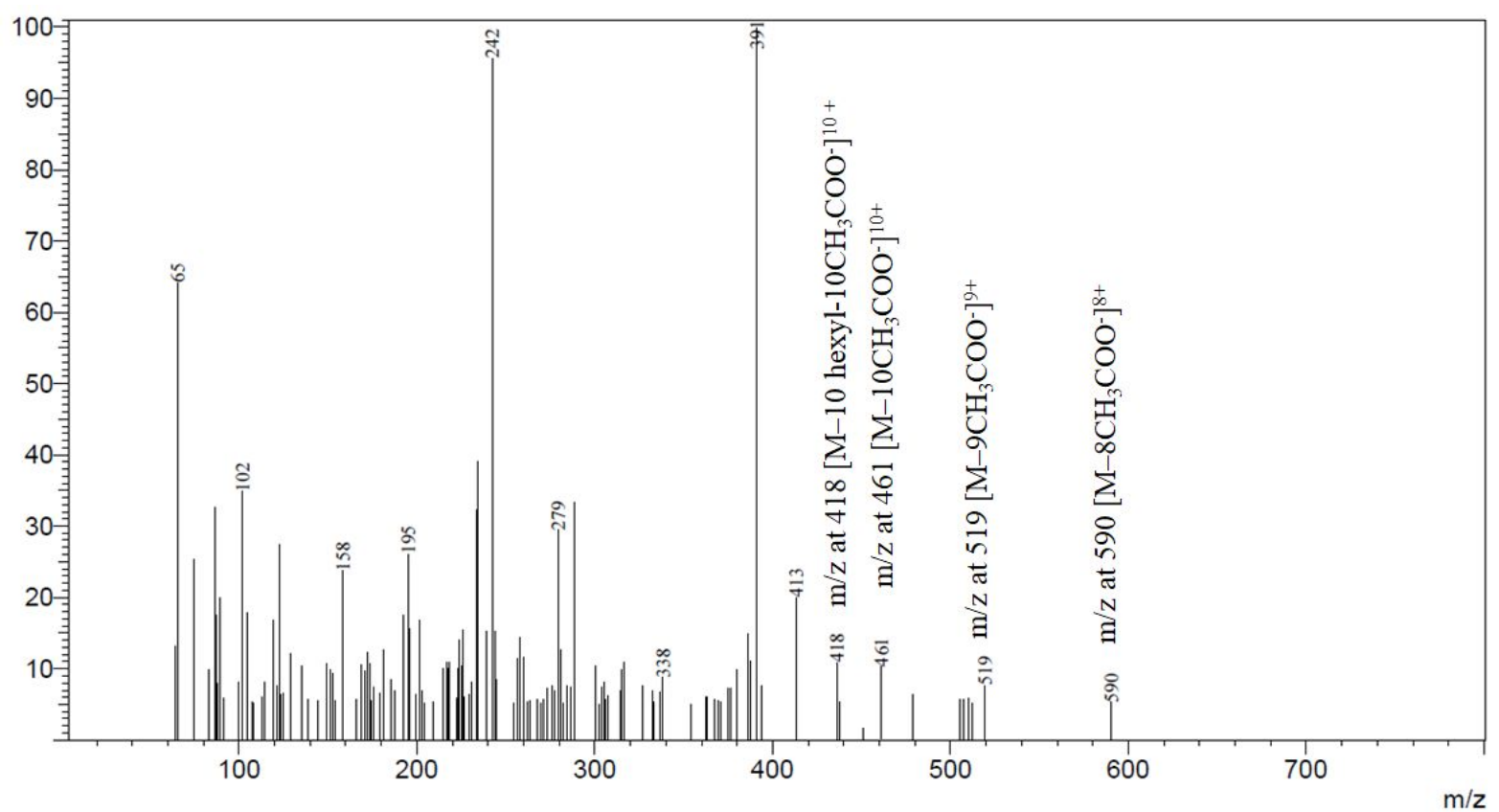

Figure S9. ESI mass spectra of $\mathrm{Fe}-\mathrm{Cz}-\mathrm{MC}$ with assigned fragments.

10. Emission spectra of $\mathrm{Fe}-\mathrm{Cz}-\mathrm{MC}$ in solid state

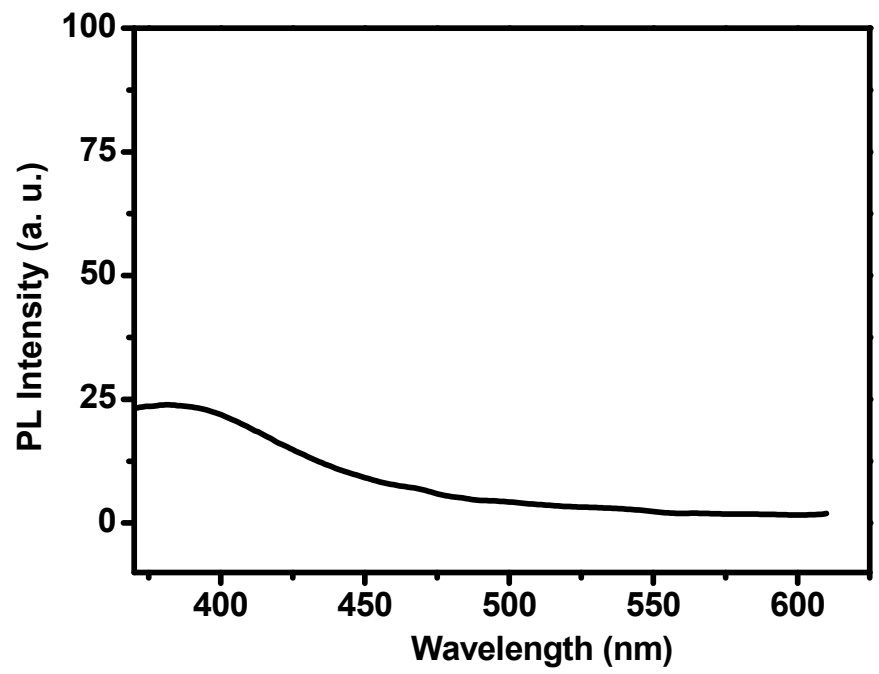

Figure S10. Emission spectra of $\mathrm{Fe}-\mathrm{Cz}-\mathrm{MC}$ in solid state. 
11. Cycle switching stability of EC measurement of Fe-Cz-MC film using three electrode and solution electrolyte

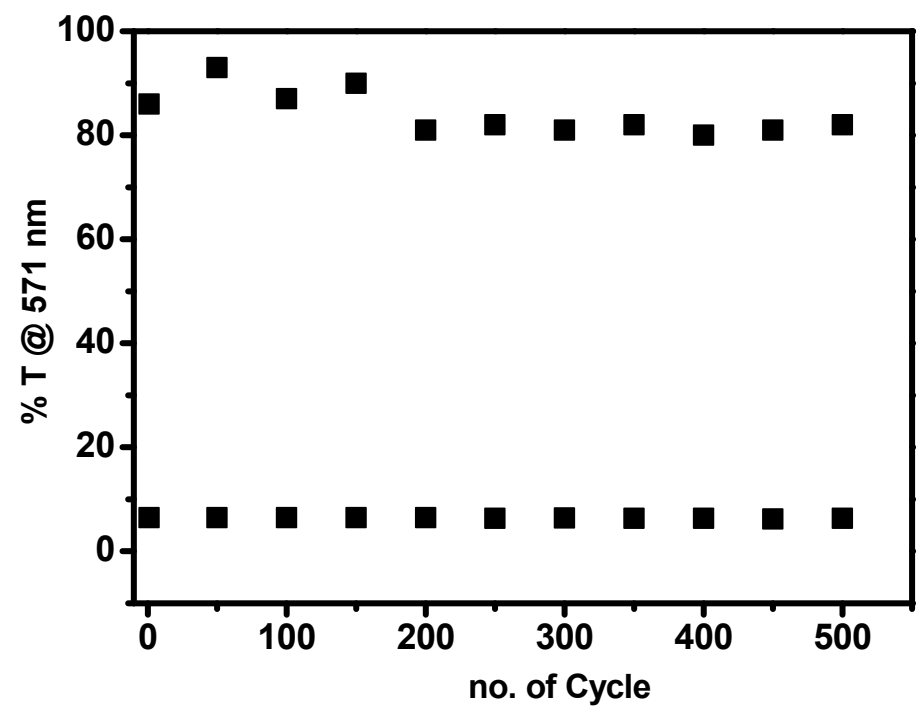

Figure S11. Cycle stability over 500 switching cycles of Fe-Cz-MC film based ECD using three electrode and solution electrolyte

12. Thickness measurement of solid state EC film by FESEM

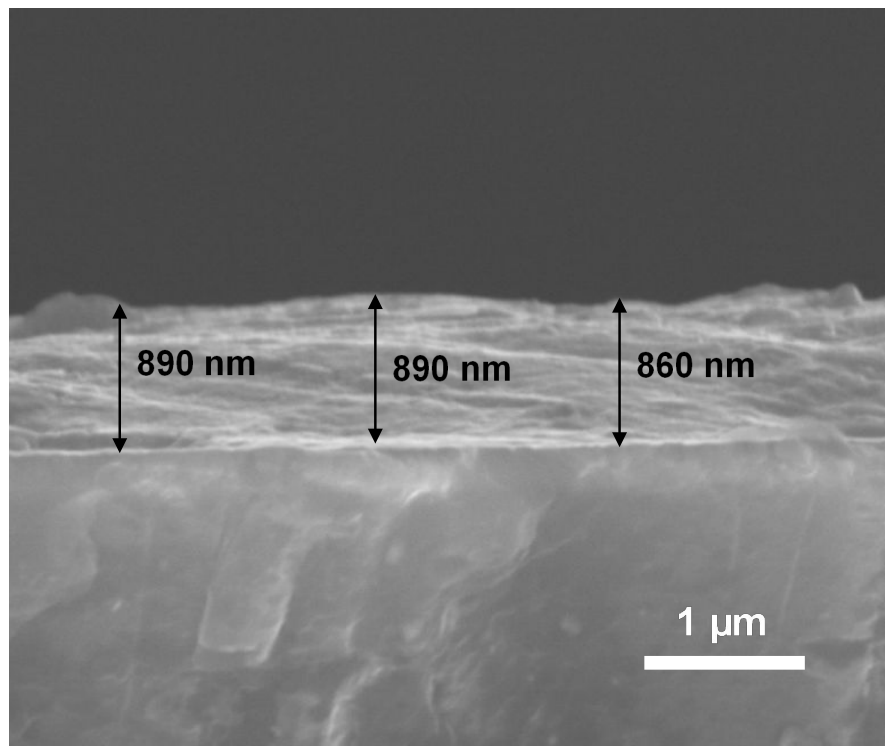

Figure S12. Cross-sectional SEM study to measure the thickness of Fe-Cz-MC film in ECD. 